\title{
Association of video gaming with some risky behaviors of secondary school adolescents in Abha, Southwestern Saudi Arabia
}

\author{
Original \\ Nabil J. Awadalla',2, Muath A. Hadram ${ }^{3}$, Ali S. Alshahrani', Yahya A. Hadram ${ }^{3}$ \\ Article \\ ${ }^{\prime}$ Department of Community Medicine, Faculty of Medicine, Mansoura University, Daqahlia, \\ Egypt. \\ ${ }^{2}$ Department of Family and Community Medicine, ${ }^{3}$ Medical Intern, College of Medicine, King \\ Khalid University, Abha, Saudi Arabia
}

\begin{abstract}
Aim: The aim of this study was to describe the patterns of video gaming among secondary school adolescents and to investigate their association with some risky behaviors.

Materials and Methods: A cross-sectional study was carried out on 336 students randomly selected from secondary schools in Abha City, Saudi Arabia, during the academic year 2015-2016. A predesigned self-report questionnaire was used to assess students' sociodemographic data, pattern, motivators and drawbacks of video gaming, previous academic year grades, history of violent acts, road traffic accidents (RTA), and violation of traffic rules. Weight and height were measured for every participant and BMI was calculated.

Results: About $80 \%$ of students played video games and $76 \%$ owned a video game machine. The median onset of video gaming was 10 years. The most important motivator for video gaming was 'give a chance for fun and excitement' (93.7\%), followed by 'give a chance to get rid of the boredom and leisure' $(92.3 \%)$. The most frequently reported social drawbacks were interfering with sleep time (69\%), physical activity (64\%), and meal time (59\%). BMI was not significantly associated with the pattern of video game playing $(P>0.05)$. Academic performance was significantly lower among students who used to game in cybercafes $(P=0.001)$. Prevalence of tobacco smoking and some risky behaviors such as traffic rule violations, significant RTA, and violence were significantly more encountered among those preferring race and drift games $(P<0.05)$ and used to game in cybercafes $(P<0.05)$.

Conclusion: Video gaming among secondary school students in Abha, Saudi Arabia, is relatively high. Some risky behaviors such as smoking, violence, significant RTA, and violation of traffic rules were significantly associated with race and drift playing and gaming in cybercafes. School-based educational programs for both adolescents and their parents should be provided to gain skills about effective time management, avoid over-gaming, risky games and gaming in cybercafes. Legal restriction on importing and selling risky video games should be considered by the government.
\end{abstract}

Revceived: 17 August 2016, Accepted: 19 January 2017

Key Words: Adolescents, body mass index, road traffic crashes, social behavior, video gaming, violence.

Corresponding Author: Nabil J. Awadalla, MD, Department of Family and Community Medicine, College of Medicine, King Khalid University, Abha, Saudi Arabia, Tel.: +96 653348 7152, E-mail: njgirgis@yahoo.co.uk.

ISSN: 0013-2446, Vol. 92, No.1

\section{INTRODUCTION}

Video games are defined as games played through an electronic system such as a computer, console, or a digital phone. It represents a very popular leisure activity among children and adolescents in Arab countries and worldwide ${ }^{[1-4]}$ and those games seem to have an influence on the behavior of adolescents ${ }^{[5]}$. Studies have shown that about $59-73 \%$ of youth were playing video games on any given day ${ }^{[6,7]}$.

There are several kinds of computer and video games which include fighting, puzzles, sports, adventure, strategy games, and others ${ }^{[8]}$. Several motivators attract the interest of the youth, especially boys in video gaming like winning, competition, challenge, adventure, enjoyable, discovery, imagination, filling leisure time, curiosity, talent development, and intelligence development ${ }^{[3]}$.

Several studies have found a relationship between video game playing and traffic-related risk behaviors, aggressive behaviors and violence among the youth ${ }^{[9,10]}$.

The problem of road traffic crashes is becoming a globally recognized problem and is the major cause of handicap and mortality in Saudi Arabia. Most of the road traffic crashes are related to drivers' errors and about 50\% are associated with excessive speed and violation of safety rules $^{[11]}$. So, it is important to explore the relation between video gaming and road traffic crashes. 
Socially, video games may drive students into social isolation, which negatively affect mental, personal, and social development. Other studies argue that video gaming may decrease the youth's physical activity and increase the risk of overweight and obesity ${ }^{[12,13]}$. Also, there is an argument about the negative impact of video gaming on the school performance of adolescents ${ }^{[14]}$.

The objectives of this study were to describe the patterns of video gaming among secondary school adolescents and to investigate their association with risky behaviors such as smoking, violence, traffic rules violation and crashes, social isolation and weight problems.

\section{MATERIALS AND METHODS}

\section{Study setting, design, and sampling}

A descriptive cross-sectional study was conducted on a representative sample of students randomly selected from 12 secondary schools for boys located in Abha City, Aseer, Southwestern Saudi Arabia in the academic year 2015-2016.

The sample size was calculated using the WHO manual for sample size determination in health researches ${ }^{[15]}$ with expected prevalence of video games playing among boys in secondary school students $76 \%{ }^{[6]}$ and with a level of absolute precision of $5 \%$ at $95 \%$ confidence. The minimal sample size required for the study was calculated to be 246 students. To account for cluster sampling error and possible nonresponse, a total sample of 340 students was intended to be included in the study.

A multistage stratified cluster sample was used to collect the participants. After enlisting male secondary schools students in Abha City, five schools were randomly selected by the simple random method. A stratified cluster random sampling was followed to randomly select one class from each grade within each school. Finally, 15 randomly selected classes with a total number of 336 students were included in the study.

\section{Study tools and data collection}

An appointment with school directors was arranged; schools were visited on separate days. All the participants were interviewed personally in their schools to measure their weight and height by the standard method using a standardized weight-height scale and then BMI was calculated according to the WHO manual ${ }^{[16]}$. Then they responded to a self-report anonymous questionnaire predesigned to collect the following data:

(1) Sociodemographic and special habits data such as age, grade, nationality, residence, education, family income, work of parents, and tobacco smoking.
(2) The participant's academic grade in the previous year. (3) Pattern of video gaming including onset, frequency, duration, place of session, cost per month in Saudi Riyal, and types of video games.

(4) Motivators of video gaming. These include: improves friend communication, a leisure activity, improves competence and autonomy, relieves stress and anxiety, fun and excitement, develops skills, and improves intellectual capabilities and increases self-esteem.

(5) Social drawbacks of video gaming such as the preference of video game playing on practicing physical activity interacting with family members and friends, eating time, and bedtime

(6) History of road traffic crashes and history of traffic rules violation in the previous 6 months. Significant road traffic crashes were considered for accidents that required hospital admissions for more than $24 \mathrm{~h}$ or associated with fracture, disability, or loss of an organ.

(7) Self-reported violence perpetration based on Krahé and Möller ${ }^{[17]}$. Students responded to a five-point scale from 0 (never) to 4 (very often) for the following questions:

(i) How often in the past 6 months they had committed verbal violence?

(ii) How often in the past 6 months they had committed kicked, hit another person?

(iii) How often in the past 6 months they had committed threats using sharp and fire weapons?

(iv) How often in the past 6 months they had committed violence using sharp and fire weapons?

(v) How often in the past 6 months they had committed sexual harassment? The mean scores for each response and the sum of all responses were calculated.

\section{Data entry and analysis}

The Statistical Package for the Social Sciences software, version 18.0 (IBM, SPSS, Chicago, Illinois, USA) was used for data entry and analysis. Descriptive statistics were presented as number and percentage for categorical data and mean and SD for continuous data.

The intensity of video gaming was divided arbitrarily according to the median cutoff point of the total weekly gaming hours. Scores above the median were considered heavy playing.

$\chi 2$-test was used to determine the association between categorical variables. Continuous variables were examined for normality distribution using Kolmogorov-Smirnov test. Student's t-test was used for parametric data whereas Mann-Whitney U-test was used for nonparametric data. A $P$ value of less than 0.05 was considered statistically significant.

\section{Ethical considerations}

The study was approved by the Ethics Committee of King Khalid University. After the official approval from the directors of selected schools, oral informed consent was obtained from the participants after explaining the 
importance of the study. Confidentiality and privacy were guaranteed for all participants.

\section{RESULTS}

The study included 336 secondary school students. Table 1 summarizes their sociodemographic characteristics. Their age ranged between 15 and 21 years with an average age of $17.2 \pm 1.03$ years. They were proportionally distributed across the different secondary school grades with the largest proportion of them in the first grade (40.8\%). The largest proportion of the students were Saudi (81\%), house owners $(61.9 \%)$, have more than satisfactory family income $(47.0 \%)$, and their fathers had more than secondary education $(67.3 \%)$ and work as governmental employers or teachers $(31.3 \%)$. Meanwhile, the largest proportion of their mothers had less than secondary education $(45.8 \%)$ and were housewives $(80.4 \%)$. About $16 \%$ of the students were tobacco smokers.

Table 1: Sociodemographic characteristics of the studied secondary school students ( $\mathrm{n}=336)$, Abha, Saudi Arabia, academic year 2015-2016

\begin{tabular}{|c|c|}
\hline Sociodemographic criteria & No. $(\%)$ \\
\hline \multicolumn{2}{|l|}{ Age (years) } \\
\hline $15-16$ & $85(25.3)$ \\
\hline $17-$ & $123(36.6)$ \\
\hline$\geq 18$ & $128(38.1)$ \\
\hline Mean \pm SD & $17.20 \pm 1.03$ \\
\hline \multicolumn{2}{|l|}{ Grade } \\
\hline $1 \mathrm{st}$ & $137(40.8)$ \\
\hline 2nd & $103(30.7)$ \\
\hline $3 \mathrm{rd}$ & $96(28.6)$ \\
\hline \multicolumn{2}{|l|}{ Father's education } \\
\hline$<$ Secondary & $79(23.5)$ \\
\hline Secondary & $31(9.2)$ \\
\hline$>$ Secondary & $226(67.3)$ \\
\hline \multicolumn{2}{|l|}{ Mother's education } \\
\hline$<$ Secondary & $154(45.8)$ \\
\hline Secondary & $51(15.2)$ \\
\hline$>$ Secondary & 131(39.0) \\
\hline \multicolumn{2}{|l|}{ Father's work } \\
\hline Governmental employer and teacher & $105(31.3)$ \\
\hline Military and Police & $66(19.6)$ \\
\hline Professional and semiprofessional & $71(21.1)$ \\
\hline Retired, died and not working & $94(28.0)$ \\
\hline \multicolumn{2}{|l|}{ Mother's work } \\
\hline Housewife & $270(80.4)$ \\
\hline Worker & $66(19.6)$ \\
\hline \multicolumn{2}{|l|}{ Housing } \\
\hline Owner & 208(61.9) \\
\hline Rent & $128(38.1)$ \\
\hline Number of family members (mean \pm SD) & $8.73 \pm 3.09$ \\
\hline \multicolumn{2}{|l|}{ Family income } \\
\hline Less than satisfactory & $81(24.1)$ \\
\hline Satisfactory & $97(28.9)$ \\
\hline More than satisfactory & $158(47.0)$ \\
\hline \multicolumn{2}{|l|}{ Nationality } \\
\hline Saudi & $272(81.0)$ \\
\hline Non-Saudi & $64(19.0)$ \\
\hline Tobacco smoking & $53(15.8)$ \\
\hline Member of sport club & $60(17.9)$ \\
\hline
\end{tabular}


Video gaming was prevalent among the studied male students $(80.7 \%)$ and $\sim 76.2 \%$ were owners of video game machine. The median age of onset of starting video games playing was 10 years. The median weekly and monthly durations, and money spent in video gaming were $12 \mathrm{~h} /$ week, $72 \mathrm{~h} /$ month, and $90 \mathrm{SR} /$ month, respectively. Around $66.4 \%$ of the students used to play video games at their homes, whereas $33.6 \%$ of the students used to play in cybercafes. Frequently preferred types of video games were fighting games (63.4\%) followed by sports games (55.4\%) and then by race and drifting games $(46.5 \%)$ and finally strategy 'war' games. Commonly reported motivators to gaming were promoting fun and excitement (93.7\%), spending interesting leisure time (92.3\%), developing skills and improving intellectual capabilities $(68.3 \%)$, promoting communication with friends $(63.1 \%)$, relieving stress and anxiety (59.4\%), improving competency and autonomy $(50.9 \%)$, and increasing self-esteem $(42.8 \%)$. The most frequently reported social and personal drawbacks of video game playing were postponing bedtime in order to end the video game $(69 \%)$, preferring to play video game to do physical activity $(64.2 \%)$, postponing meal time in order to end the game $(59.4 \%)$, and preferring to play video games to play or talk with friends $(53.5 \%)$ or family interaction $(52 \%)$. In addition, more than one-third of the students reported family troubles because of video game playing $(35.4 \%)$ and perceived video game playing as addiction (34.7\%) (Table 2).

Table 2: Pattern, motivators and drawbacks of video gaming among studied secondary school students ( $\mathrm{n}=336$ ), Abha, Saudi Arabia, academic year 2015-2016

\begin{tabular}{|c|c|}
\hline Pattern, motivators and drawbacks of Video gaming & No $(\%)$ \\
\hline Rate of video game users & $271(80.7)$ \\
\hline Having video game machine at home & $256(76.2)$ \\
\hline \multicolumn{2}{|l|}{ Onset of start playing video games (years) } \\
\hline $5-10$ & $118(43.5)$ \\
\hline$\geq 10$ & $153(56.4)$ \\
\hline Median (range) & $10 \quad(4-18)$ \\
\hline \multicolumn{2}{|l|}{ Duration of playing video games (month) } \\
\hline Median (range) & $72(1-180)$ \\
\hline \multicolumn{2}{|l|}{ Video games playing hours/ week } \\
\hline Median (range) & $12(1-84)$ \\
\hline \multicolumn{2}{|l|}{ Money spent in playing videogames (Riyal/month) } \\
\hline Median (range) & $90 \quad(0.00-500)$ \\
\hline \multicolumn{2}{|l|}{ Types of preferred video games } \\
\hline Fighting games & $172(63.4)$ \\
\hline Race & $156(46.5)$ \\
\hline Sports & $186(55.4)$ \\
\hline Strategy "war games" & $116(34.7)$ \\
\hline \multicolumn{2}{|l|}{ Site of video games playing } \\
\hline Home only & $180(66.4)$ \\
\hline Cyber cafes and home & $91(33.6)$ \\
\hline \multicolumn{2}{|l|}{ Motivators for video gaming ${ }^{\mathrm{a}}$} \\
\hline Improve friend communication & $171 \quad(63.1)$ \\
\hline Improve competency and autonomy & $138 \quad(50.9)$ \\
\hline Interesting leisure activity & $250 \quad(92.3)$ \\
\hline Relieve stress and anxiety & $161 \quad(59.4)$ \\
\hline Promoting fun and excitement & $254 \quad(93.7)$ \\
\hline Develop skills and improve intellectual capabilities & $185 \quad(68.3)$ \\
\hline Increase self-esteem & $116 \quad(42.8)$ \\
\hline \multicolumn{2}{|l|}{ Social and personal drawbacks ${ }^{\mathrm{a}}$} \\
\hline Preference of playing video games to do physical activity & $174 \quad(64.2)$ \\
\hline
\end{tabular}


Preference of playing video games to play or talk with Friends

Preference of playing video games to family sharing

Postpone bedtime in order to end the game

Postpone mealtime in order to end the game

Postpone going to the toilet in order to end the game

Family troubles because of video game playing

Perception video game playing as addiction

${ }^{a}$ Data were not mutually exclusive

Relations between the pattern of video gaming and smoking, BMI, and scholastic achievement among the studied students are shown in Table 3. The frequency of tobacco smoking was nonsignificantly higher $(P>0.05)$ among video gaming students, heavy gaming, earlier onset of video gaming, and those who perceived video gaming as addiction. On the other hand, tobacco smoking was

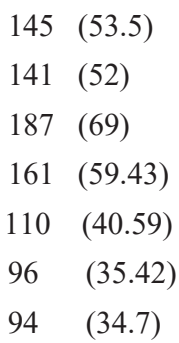

significantly higher $(P<0.05)$ among students preferring race and drift games and used to game in cybercafes. There were no significant associations $(P>0.05)$ between BMI and patterns of video gaming. Meanwhile, academic performance was significantly lower $(P=0.001)$ among students who start playing video games earlier (before 10 years of age) and used to game in cybercafes.

Table 3: Relations between pattern of video gaming and smoking, BMI and scholastic achievement of secondary school students ( $\mathrm{n}=336$ ), Abha, Saudi Arabia, academic year 2015-2016

\begin{tabular}{|c|c|c|c|c|c|c|}
\hline Video gaming pattern & $\begin{array}{l}\text { Smoking } \\
\text { No. }(\%)\end{array}$ & $\begin{array}{c}\chi^{2} \\
(\mathrm{P}-\mathrm{value})^{\mathrm{a}}\end{array}$ & $\begin{array}{c}\text { BMI } \\
\text { Mean } \pm \text { SD }\end{array}$ & $\begin{array}{c}\mathrm{t} \\
(\mathrm{P}-\mathrm{value})^{\mathrm{b}}\end{array}$ & $\begin{array}{c}\text { Previous } \\
\text { year grade } \\
\text { Mean } \pm \text { SD }\end{array}$ & $\begin{array}{c}\mathrm{t} \\
(\mathrm{P}-\mathrm{value})^{\mathrm{b}}\end{array}$ \\
\hline \multicolumn{7}{|l|}{ Video gaming $(n=336)$} \\
\hline Yes & $42(15.5)$ & 0.08 & $24.54 \pm 7.04$ & 0.29 & $88.42 \pm 9.37$ & 0.53 \\
\hline No & $11(16.9)$ & $(0.85)$ & $23.54 \pm 5.73$ & $(0.23)$ & $87.73 \pm 6.45$ & $(0.5)$ \\
\hline \multicolumn{7}{|c|}{ Gaming intensity $(\mathrm{n}=336)$} \\
\hline No and Low & $30(15.4)$ & 0.05 & $24.57 \pm 7.11$ & 0.51 & $87.78 \pm 8.59$ & 0.31 \\
\hline Heavy playing & $23(16.3)$ & $(0.88)$ & $24.02 \pm 6.36$ & $(0.46)$ & $89.04 \pm 9.32$ & $(0.22)$ \\
\hline \multirow[t]{2}{*}{ Perceived as addiction } & $13(13.8)$ & 0.31 & $24.65 \pm 6.33$ & 0.03 & $88.98 \pm 9.11$ & 0.5 \\
\hline & & $(0.72)$ & $24.48 \pm 7.41$ & $(0.84)$ & $88.13 \pm 9.52$ & $(0.48)$ \\
\hline \multicolumn{7}{|l|}{ Onset (years) $(n=263)$} \\
\hline $5-10$ & $18(16.2)$ & 0.81 & $23.61 \pm 8.73$ & 0.21 & $82.00 \pm 17.07$ & 3.96 \\
\hline$>10$ & $20(13.1)$ & $(0.66)$ & $24.51 \pm 6.75$ & $(0.34)$ & $88.60 \pm 8.70$ & $(0.001)^{*}$ \\
\hline \multicolumn{7}{|c|}{ Preferred games $(n=263)$} \\
\hline Fighting games & $27(15.7)$ & 0.02 & $24.25 \pm 6.52$ & 0.89 & $88.34 \pm 9.43$ & 0.17 \\
\hline & & $(0.9)$ & & $(0.37)$ & & $(0.86)$ \\
\hline \multirow[t]{2}{*}{ Race and drifting } & $32(20.5)$ & 6.76 & $24.52 \pm 6.84$ & 0.05 & $87.55 \pm 9.75$ & 1.66 \\
\hline & & $(0.01)^{*}$ & & $(0.86)$ & & $(0.09)$ \\
\hline \multirow[t]{2}{*}{ Sports } & $28(15.1)$ & 0.12 & $24.67 \pm 7.36$ & 0.4 & $88.34 \pm 9.44$ & 0.24 \\
\hline & & $(0.72)$ & & $(0.69)$ & & $(0.81)$ \\
\hline \multirow[t]{2}{*}{ Strategy games } & $23(19.8)$ & 2.82 & $24.38 \pm 7.18$ & 0.19 & $87.51 \pm 10.04$ & 1.34 \\
\hline & & -0.13 & & $(0.85)$ & & $(0.18)$ \\
\hline \multicolumn{7}{|l|}{ Site of gaming $(n=263)$} \\
\hline \multirow{2}{*}{$\begin{array}{l}\text { Home } \\
\text { Cyber cafes }\end{array}$} & $20(11.1)$ & 7.79 & $24.50 \pm 6.69$ & 0.37 & $89.87 \pm 8.81$ & 3.4 \\
\hline & $22(24.2)$ & $(0.02)^{*}$ & $23.22 \pm 4.69$ & $(0.71)$ & $85.51 \pm 10.11$ & $(0.001)^{*}$ \\
\hline
\end{tabular}

$\mathrm{BMI}=$ Body mass index, a Chi-square test, $\mathrm{b}$ Independent $\mathrm{t}$-test $*$ Significant at $\mathrm{P}<0.05$ 
The relations between the pattern of video gaming and violation of traffic rules and RTA at least once during the preceding 6 months are shown in Table 4. Violation of traffic rules like exceeding speed limits, crossing the red signal, and practicing drift were significantly higher
$(P<0.05)$ among students who preferred race and drift gaming and among those who used to game in cybercafes. Moreover, the frequency of significant road traffic crashes was significantly higher $(P<0.05)$ among students who preferred to play race and drift video games.

Table 4: Relations between pattern of video gaming and violation of traffic rules and RTA at least once during the preceding 6 months $(\mathrm{n}=277)$ in secondary school students $(\mathrm{n}=336)$, Abha, Saudi Arabia, academic year 2015-2016

\begin{tabular}{|c|c|c|c|c|c|c|}
\hline $\begin{array}{l}\text { Video gaming } \\
\text { pattern }\end{array}$ & $\begin{array}{l}\text { Exceed the } \\
\text { speed limits }\end{array}$ & $\begin{array}{l}\text { Cross the } \\
\text { red signal }\end{array}$ & $\begin{array}{l}\text { Not wearing } \\
\text { the seat belt }\end{array}$ & $\begin{array}{l}\text { Practicing } \\
\text { drift }\end{array}$ & $\begin{array}{l}\text { Significant } \\
\text { RTA }\end{array}$ & $\begin{array}{c}\text { RTA with less than } \\
24 \text { hrs hospital } \\
\text { admission }\end{array}$ \\
\hline \multicolumn{7}{|l|}{ Gaming intensity } \\
\hline No and Low & $95(57.9 \%)$ & $57(34.8 \%)$ & $130(79.3 \%)$ & $56(34.1 \%)$ & $22(13.4 \%)$ & $46(23.1 \%)$ \\
\hline Heavy & $67(59.3 \%)$ & $32(28.3 \%)$ & $93(82.3 \%)$ & $34(30.1 \%)$ & $22(19.5 \%)$ & $45(32.8 \%)$ \\
\hline$\chi^{2}(p-\text { value })^{\mathrm{a}}$ & $0.01(0.94)$ & $0.82(0.29)$ & $0.29(0.64)$ & $0.45(0.51)$ & $1.09(0.18)$ & $3.42(0.06)$ \\
\hline \multicolumn{7}{|l|}{ Preferred games } \\
\hline Fighting games & $89(61.0 \%)$ & $47(2.2 \%)$ & $123(84.2 \%)$ & $53(36.3 \%)$ & $26(17.8 \%)$ & $45(26.2 \%)$ \\
\hline Others & $45(57.0 \%)$ & $23(29.1 \%)$ & $62(78.5 \%)$ & $23(29.1 \%)$ & $8(10.1 \%)$ & $31(31.3 \%)$ \\
\hline$\chi^{2}(p-$ value $)$ & $0.34(0.57)$ & $0.28(0.65)$ & $0.81(0.28)$ & $0.95(0.30)$ & $1.21(0.17)$ & $1.11(0.40)$ \\
\hline Race and drift & $88(66.7 \%)$ & $53(40.2 \%)$ & $108(81.8 \%)$ & $58(43.9 \%)$ & $25(18.9 \%)$ & $48(30.8 \%)$ \\
\hline Others & $45(49.5 \%)$ & $17(18.7 \%)$ & $76(83.5 \%)$ & $18(19.8 \%)$ & $9(9.9 \%)$ & $28(24.8 \%)$ \\
\hline$\chi^{2}(p-$ value $)$ & $6.63(0.01)^{*}$ & $11.53(0.001)^{*}$ & $0.11(0.85)$ & $12.4(0.001)^{*}$ & $3.81(0.049)^{*}$ & $1.29(0.33)$ \\
\hline Sports & $88(55.7 \%)$ & $47(29.7 \%)$ & $124(78.5 \%)$ & $50(31.6 \%)$ & $23(14.6 \%)$ & $46(24.7 \%)$ \\
\hline Others & $46(69.7 \%)$ & $23(34.8 \%)$ & $60(90.9 \%)$ & $26(39.4 \%)$ & $11(16.7 \%)$ & $30(35.7 \%)$ \\
\hline$\chi^{2}(p$-value $)$ & $3.71(0.05)$ & $0.56(0.52)$ & $4.53(0.03)^{*}$ & $0.89(0.28)$ & $0.31(0.61)$ & $3.75(0.05)$ \\
\hline Strategy games & $59(60.8 \%)$ & $32(33.0 \%)$ & $81(83.5 \%)$ & $38(39.2 \%)$ & $16(16.5 \%)$ & $35(30.2 \%)$ \\
\hline Others & $74(58.3 \%)$ & $38(29.9 \%)$ & $104(81.9 \%)$ & $38(29.9 \%)$ & $18(14.2 \%)$ & $41(26.6 \%)$ \\
\hline$\chi^{2}(p-v a l u e)$ & $0.15(0.78)$ & $0.24(0.66)$ & $0.09(0.86)$ & $1.21(0.15)$ & $0.25(0.71)$ & $0.34(0.59)$ \\
\hline \multicolumn{7}{|l|}{ Site of gaming } \\
\hline Home & $72(51.8 \%)$ & $33(23.7 \%)$ & $113(81.3 \%)$ & $37(26.6 \%)$ & $16(11.5 \%)$ & $52(28.9 \%)$ \\
\hline Cyber cafes & $62(72.2 \%)$ & $37(43.0 \%)$ & $72(83.7 \%)$ & $39(45.3 \%)$ & $18(20.9 \%)$ & $24(27.9 \%)$ \\
\hline$\chi^{2}(p-$ value $)$ & $9.01(0.002)^{*}$ & $10.77(0.001)^{*}$ & $0.27(0.64)$ & $7.89(0.003)^{*}$ & $3.41(0.06)$ & $0.09(0.87)$ \\
\hline
\end{tabular}

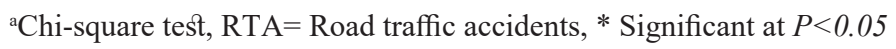


Heavy video gaming was significantly associated with higher verbal violence score. Preferring to play race and drift games was significantly associated with higher scores of total violence, physical violence, violence using firearms, and sexual harassment. Also, gaming in cybercafes was significantly associated with higher scores of total violence and physical violence (Table 5).

Table 5: Relations between pattern of video gaming and violence scores during the preceding 6 months. in secondary school students, Abha, Saudi Arabia, academic year 2015-2016

\begin{tabular}{|c|c|c|c|c|c|c|c|c|}
\hline $\begin{array}{l}\text { Video gaming } \\
\text { pattern }\end{array}$ & $\begin{array}{l}\text { Total } \\
\text { violence } \\
\text { score }\end{array}$ & $\begin{array}{l}\text { Verbal } \\
\text { violence }\end{array}$ & $\begin{array}{l}\text { Physical } \\
\text { violence }\end{array}$ & $\begin{array}{l}\text { Threat } \\
\text { using } \\
\text { sharps }\end{array}$ & $\begin{array}{l}\text { Threats } \\
\text { using } \\
\text { firearms }\end{array}$ & $\begin{array}{l}\text { Violence } \\
\text { using sharps }\end{array}$ & $\begin{array}{l}\text { Violence } \\
\text { using } \\
\text { firearms }\end{array}$ & $\begin{array}{c}\text { Sexual } \\
\text { harassment }\end{array}$ \\
\hline \multicolumn{9}{|l|}{$\begin{array}{l}\text { Video gaming } \\
\text { intensity }\end{array}$} \\
\hline $\begin{array}{l}\text { No and Low } \\
\text { (139) }\end{array}$ & $0.32 \pm 1.02$ & $0.32 \pm 1.02$ & $1.45 \pm 1.23$ & $0.43 \pm 0.94$ & $0.28 \pm 0.87$ & $0.34 \pm 0.89$ & $0.25 \pm 0.81$ & $0.42 \pm 0.96$ \\
\hline Heavy (137) & $0.38 \pm 0.96$ & $0.38 \pm 0.96$ & $1.57 \pm 1.30$ & $0.47 \pm 1.02$ & $0.25 \pm 0.78$ & $0.43 \pm 1.01$ & $0.20 \pm 0.75$ & $0.57 \pm 1.05$ \\
\hline$Z^{\mathrm{a}}$ & 1.91 & 1.91 & -0.72 & -0.24 & -0.15 & -0.91 & -0.67 & -1.79 \\
\hline P-value & 0.07 & 0.07 & 0.47 & 0.81 & 0.88 & 0.36 & 0.5 & 0.07 \\
\hline \multicolumn{9}{|l|}{ Preferred games } \\
\hline Fighting (172) & $0.36 \pm 1.01$ & $0.36 \pm 1.01$ & $1.56 \pm 1.30$ & $0.45 \pm 1.02$ & $0.26 \pm 0.84$ & $0.42 \pm 1.03$ & $0.28 \pm 0.88$ & $0.51 \pm 1.01$ \\
\hline Others (99) & $0.32 \pm 1.06$ & $0.32 \pm 1.06$ & $1.49 \pm 1.17$ & $0.47 \pm 0.95$ & $0.26 \pm 0.83$ & $0.33 \pm 0.90$ & $0.23 \pm .78$ & $0.53 \pm 1.01$ \\
\hline Z & 0.65 & 0.65 & 0.32 & 0.77 & 0.11 & 0.74 & 0.05 & 0.03 \\
\hline P-value & 0.51 & 0.51 & 0.75 & 0.44 & 0.91 & 0.46 & 0.96 & 0.97 \\
\hline $\begin{array}{l}\text { Race and } \\
\text { drift (156) }\end{array}$ & $0.48 \pm 1.23$ & $0.48 \pm 1.23$ & $1.67 \pm 1.25$ & $0.65 \pm 1.16$ & $0.38 \pm 1.01$ & $0.58 \pm 1.19$ & $0.38 \pm 1.01$ & $0.65 \pm 1.15$ \\
\hline Others (113) & $0.17 \pm 0.64$ & $0.17 \pm 0.64$ & $1.36 \pm 1.25$ & $0.20 \pm 0.64$ & $0.10 \pm 0.46$ & $0.14 \pm 0.53$ & $0.11 \pm 0.52$ & $0.34 \pm 0.76$ \\
\hline $\mathrm{Z}$ & 2.32 & 2.32 & 2.05 & 3.55 & 2.87 & 3.59 & 2.63 & 2.26 \\
\hline P-value & $0.02 *$ & $0.02 *$ & $0.04 *$ & $0.001 *$ & $0.001 *$ & $0.001 *$ & $0.01 *$ & $0.02 *$ \\
\hline Sports (186) & $0.26 \pm 0.67$ & $0.26 \pm 0.67$ & $1.52 \pm 1.20$ & $0.36 \pm 0.84$ & $0.17 \pm 0.68$ & $0.32 \pm 0.90$ & $0.18 \pm 0.72$ & $0.48 \pm 0.91$ \\
\hline Others (84) & $0.52 \pm 1.53$ & $0.52 \pm 1.53$ & $1.57 \pm 1.36$ & $0.63 \pm 1.20$ & $0.45 \pm 1.08$ & $0.51 \pm 1.09$ & $0.44 \pm 1.06$ & $0.60 \pm 1.21$ \\
\hline Z & 0.23 & 0.23 & 0.11 & 1.65 & 2.65 & 1.67 & 2.91 & 0.01 \\
\hline$P$-value & 0.82 & 0.82 & 0.92 & 0.1 & $0.01 *$ & 0.09 & $0.001 *$ & 0.99 \\
\hline $\begin{array}{l}\text { Strategy and } \\
\text { wars (116) }\end{array}$ & $0.39 \pm 1.01$ & $0.39 \pm 1.01$ & $1.51 \pm 1.31$ & $0.56 \pm 1.03$ & $0.34 \pm 0.91$ & $0.49 \pm 1.08$ & $0.36 \pm 0.97$ & $0.54 \pm 1.06$ \\
\hline Others (154) & $0.32 \pm 1.05$ & $0.32 \pm 1.05$ & $1.56 \pm 1.21$ & $0.38 \pm 0.96$ & $0.21 \pm 0.76$ & $0.32 \pm 0.91$ & $0.19 \pm 0.73$ & $0.50 \pm 0.98$ \\
\hline Z & 1.52 & 1.52 & 0.53 & 1.99 & 1.59 & 1.5 & -1.64 & 0.26 \\
\hline P-value & 0.13 & 0.13 & 0.6 & 0.05 & 0.11 & 0.13 & 0.11 & 0.79 \\
\hline \multicolumn{9}{|l|}{ Site of gaming } \\
\hline Home (180) & $0.27 \pm 0.86$ & $1.68 \pm 1.14$ & $1.39 \pm 1.18$ & $0.38 \pm 0.90$ & $0.22 \pm 0.79$ & $0.33 \pm 0.90$ & $0.21 \pm 0.74$ & $0.43 \pm 0.93$ \\
\hline Cyber cafes (91) & $0.56 \pm 1.38$ & $1.61 \pm 1.24$ & $1.97 \pm 1.31$ & $0.62 \pm 1.15$ & $0.39 \pm 0.98$ & $0.52 \pm 1.14$ & $0.42 \pm 1.09$ & $0.75 \pm 1.18$ \\
\hline Z & -2.17 & -0.81 & -3.3 & -1.51 & -1.57 & -1.32 & -1.49 & -2.22 \\
\hline P-value & $0.03 *$ & 0.42 & $0.001^{*}$ & 0.13 & 0.12 & 0.19 & 0.14 & $0.03 *$ \\
\hline
\end{tabular}

${ }^{\text {a} M a n n-W h i t n e y ~ U ~ t e s t, ~ * ~ S i g n i f i c a n t ~ a t ~} P<0.05$ 


\section{DISCUSSION}

The present study showed that the majority of secondary school boys (80.7\%) in Abha City, Southwestern Saudi Arabia were video gamers. This is in conformity with a recent Saudi study conducted in Makkah $\mathrm{City}^{[3]}$, but slightly higher than that previously reported among high school boys in the USA $(76.6 \%)^{[6]}$ and lower than that reported in a recent systematic review $(90 \%)^{[18]}$.

In the present study, the median age of gaming initiation was 10 years and that of gaming intensity was $12 \mathrm{~h} /$ week. A similar pattern was reported in the study conducted in Makkah, $\mathrm{KSA}^{[3]}$. However, other studies have shown video gaming intensity to range between 10 and $20 \mathrm{~h} /$ week $^{[19-21]}$.

Most of the students in the current study preferred playing fighting (63.4\%) and sports video games $(46.5 \%)$. This was in accordance with a Saudi study conducted by Alqurashi et al. ${ }^{[3]}$. Miller ${ }^{[22]}$ attributed boys' preference of fighting games to their inherent characteristics of working on short-term memory, repeated actions, and risk taking.

In agreement with other studies ${ }^{[3,23]}$, the current study has shown that the most frequently reported motivators of gaming by adolescents were promoting fun and excitement, spending interesting leisure time, and developing skills and improving intellectual capabilities. This high level of motivation detected in the current study should encourage the authorities of education to integrate gaming in the educational process of secondary school students as recommended by Weis and Cerankosky ${ }^{[24]}$.

Preferring video gaming than interacting with friends or family members were among the most commonly reported negative social drawbacks of video gaming by adolescents in the current study. These findings are in line with the findings of a study done by Unsworth et al. ${ }^{[25]}$ and supports the explanation that video games may drive adolescents into social isolation, which negatively affect their mental, personal, and social development.

Moreover, the majority of the students $(64.2 \%)$ in the current study preferred gaming to physical activity. Grüsser et al. ${ }^{[26]}$ in their study indicated that adolescent video gamers suffered considerable reduction in their physical activity and were more likely to continue sedentary activity behaviors into adulthood.

More than half of the studied students in the current study reported that video gaming postponed their sleep and mealtime. This is considerably higher than that reported by Griffiths et al. ${ }^{[27]}$ who reported that $20 \%$ of students sacrifice sleep and other healthy habits when playing video games. Moreover, our results have shown that about one-third of the students considered themselves as "video game addicts'. A systematic review concluded that gaming addiction became a widespread serious problem that is still difficult to be treated, more distressing than alcohol or drug addiction and may result in several unwanted consequences including obsession with gaming, no real-life relationships, inattention, aggressive/oppositional behavior and hostility, sacrificing hobbies, sleep, work, education, socializing, and time with partner/family ${ }^{[19]}$.

The present study has shown that tobacco smoking was significantly associated with two specific patterns of gaming; playing race and drift games and playing in cybercafes. In support, Fischer et al. ${ }^{[10]}$ found that watching risk-glorifying movies or playing risk-taking video games like racing is associated with increased risk-taking behaviors particularly smoking. Furthermore, it has been indicated that smoking behavior could be predicted by exposure to smoking in cybercafes rather than the length and duration of playing ${ }^{[28]}$.

In contradiction to previous studies, the current study has shown insignificant associations between different patterns of video gaming including duration, onset, and types of preferred games and the BMI of the studied students. Weaver et al. ${ }^{[29]}$ and Ballard et al. ${ }^{[30]}$ found a positive significant association between time spent in video gaming and BMI and attributed this finding to the associated sedentary activity pattern and low physical activity. However, there might be several explanations for our findings. Perhaps missed or delayed meals and irregular sleep reported by more than 59 and $69 \%$ of the studied students in order to complete the game are possible factors. There may also be energy expenditure resulted from physical, emotional, and physiological interactions with fighting, racing and sports video games, and interactive video games ${ }^{[31]}$. These factors may oppose the sedentary behavior effect of video gaming on BMI and keep it within the normal range.

In the current study, the academic performance was not significantly associated with the time spent in video gaming or with a specific type of video game. Actually, there is a controversy on the effect of video game playing on academic performance. One study considered no effect $^{[32]}$, and another study reported that video games can improve the students' thinking skills and improve their learning capabilities ${ }^{[3]}$. On the contrary, another study concluded that video games addiction may be associated with decreased academic performance, verbal memory performance, and sacrificing sleep and education [33]. This controversy could be explained by individual variability related to time management skills and intellectual abilities $^{[33]}$. Another possibility is related to the type of video game; some video games may improve thinking and creativity like problem-solving strategies and educational video games, whereas other games may only fill the leisure time without motivating thinking or creativity ${ }^{[34]}$.

The present study has shown that both violation of traffic rules and frequency of RTA were significantly higher among students who preferred to play race and drifting video games. These findings are in agreement with a study that found a strong relation between playing driving-related video games that motivate fast or reckless driving and the attitudes toward aggressive undisciplined 
driving with a higher possibility of violation of traffic rules and accidents ${ }^{[35]}$.

According to the findings of the current study, some violent behaviors were associated significantly with certain patterns of video gaming like heavy playing, playing the race and drifting games, and playing in cybercafes. Involvement in violent video games has been linked to aggressive cognitions and behaviors, desensitization to violence, and decrease in prosocial behavior ${ }^{[9]}$. Another study additionally proposes that interactive involvement with violent video games may enhance hostility more than an equivalent time of passive exposure to violent movies, newspapers, or other traditional forms of media ${ }^{[36]}$.

Collectively, the present study has shown significant positive associations between video gaming in cybercafes and risky behaviors namely smoking, violence, violation of traffic rules, and road traffic crashes. These findings could be attributed to the fact that critical years of adolescence are characterized by independence seeking, tendency to disengage from parental control and concern with opinions of other people as those at cybercafes and peers.

\section{LIMITATIONS}

Among the strengths of the current study, its unique nature, as far as our knowledge goes, this is the first study to be conducted among secondary school boys in Southwestern Saudi Arabia to identify the pattern of video gaming and to investigate its association with risky behaviors. However, this study had some limitations that should be mentioned. First, the researchers relied on history taking to assess most of the studied risky behaviors that could be a source of bias. Also, data collection realized mainly on self-report even though the authors made every effort to minimize any possible over-reporting or underreporting by the participants. Besides, as this is a crosssectional study, the temporality of the associations between gaming and the related problems cannot be certain and it is difficult to make a causal relationship. Also, being a crosssectional design it provides only an existing snapshot of the problem that might become different if the time is changed.

\section{CONCLUSION}

Video gaming among secondary school students in Abha, Saudi Arabia, is relatively high. Certain social and personal drawbacks are frequently reported with video gaming and some risky behaviors such as smoking, violence, significant RTA, and violation of traffic rules are significantly associated with race and drift playing and gaming in cybercafes. Prospective and interventional studies are needed to verify the results. School-based educational programs should be provided to adolescents to gain skills about how to manage their time effectively, avoid over-gaming, and avoid violent games. Parents should be aware about the hazards of over-gaming, risky games, and gaming in cybercafes on the health and behavior of their children. Legal restriction on importing and selling risky video games should be studied by the government.

\section{CONFLICT OF INTEREST}

There are no conflicts of interest.

\section{REFERENCES}

1. Mumtaz S. Children's enjoyment and perception of computer use in the home and the school. Comput Educ 2001; 36:347-362.

2. Nippold MA, Duthie JK, Larsen J. Literacy as a leisure activityfree-time preferences of older children and young adolescents. Lang Speech Hear Serv Sch 2005; 36:93-102.

3. Alqurashi M, Almoslamani $\mathrm{Y}$, Alqahtani A. Middle school students'digital game experiences in the city of makkah in Saudi Arabia. Int E-J Ady Educ 2016; 2:167-175.

4. Malliet S. Adapting the principles of ludology to the method of video game content analysis. Game Stud 2007; 7:1

5. Papastergiou M. Use of a course management system based on Claroline to support a social constructivist inspired course: a Greek case study. Educ Media Int 2007; 44:43-59.

6. Desai RA, Krishnan-Sarin S, Cavallo D, Potenza MN. Video-gaming among high school students: health correlates, gender differences, and problematic gaming. Pediatrics 2010; 126:e1414-e1424.

7. Roberts D, Foehr U, Rideout V. Generation M: media in the lives of 8-18 year-olds. Menlo Park, CA: Henry J Kaiser Foundation 2005.

8. Christopher TV. Using game theory techniques and concepts to develop proprietary models for use in intelligent games (Order No. 3450446). 2011Úvailable from ProQuest Central; ProQuest Dissertations and Theses Global. (864734679). [Accessed, 2016, June, 11], Available from: https://search.proquest. com/docview/864734679?accountid=30902.

9. Anderson CA, Bushman BJ. Effects of violent video games on aggressive behavior, aggressive cognition, 
aggressive affect, physiological arousal, and prosocial behavior: a meta-analytic review of the scientific literature. Psychol Sci 2001; 12:353-359.

10. Fischer $\mathrm{P}$, Vingilis $\mathrm{E}$, Greitemeyer $\mathrm{T}$, Vogrincic C. Risk-taking and the media. Risk Anal 2011; 31:699-705.

11. Ansari S, Akhdar F, Mandoorah M, Moutaery K. Causes and effects of road traffic accidents in Saudi Arabia. Public Health 2000; 114:37-39.

12. Sothern MS. Obesity prevention in children: physical activity and nutrition. Nutrition 2004; 20:704-708.

13. Shen C, Williams D. Unpacking time online: connecting internet and massively multiplayer online game use with psychosocial well-being. Communic Res 2011; 38:123-149.

14. Sharif I, Sargent JD. Association between television, movie, and video game exposure and school performance. Pediatrics 2006; 118:e1061-e1070.

15. Lwanga SK, Lemeshow S. Sample size determination in health studies: a practical manual. Geneva: World Health Organization; 1991.

16. Status WP. The use and interpretation of anthropometry. Geneva: WHO; 1995. (technical report no. 854)

17. Krahé B, Möller I. Playing violent electronic games, hostile attributional style, and aggressionrelated norms in German adolescents. J Adolesc $2004 ; 27: 53-69$.

18. Forsyth SR, Malone RE. Smoking in video games: a systematic review. Nicotine Tob Res 2016; 18:1390-1398.

19. Kuss DJ, Griffiths MD. Internet gaming addiction: a systematic review of empirical research. Int J Ment Health Addict 2012; 10:278-296.

20. Kowert R, Oldmeadow JA. (A) Social reputation: exploring the relationship between online video game involvement and social competence. Comput Human Behav 2013; 29:1872-1878.

21. Lemmens JS, Valkenburg PM, Peter J. Psychosocial causes and consequences of pathological gaming. Comput Human Behav 2011; 27:144-152.

22. Miller CT. Games: purpose and potential in education. New York, NY: Springer Science and Business Media; 2008.
23. Olson CK, Kutner LA, Warner DE. The role of violent video game content in adolescent development boys' perspectives. J Adolesc Res 2008; 23:55-75.

24. Weis R, Cerankosky BC. Effects of video-game ownership on young boys' academic and behavioral functioning a randomized, controlled study. Psychol Sci. 2010; 21:463-470.

25. Unsworth G, Devilly GJ, Ward T. The effect of playing violent video games on adolescents: should parents be quaking in their boots? Psychol Crime Law 2007; 13:383-394.

26. Grüsser SM, Thalemann R, Griffiths MD. Excessive computer game playing: evidence for addiction and aggression? Cyberpsychol Behav 2006; 10:290-292.

27. Griffiths MD, Davies MN, Chappell D. Demographic factors and playing variables in online computer gaming. Cyberpsychol Behav 2004; 7:479-487.

28. Wills TA, Sargent JD, Stoolmiller M, Gibbons FX, Gerrard M. Movie smoking exposure and smoking onset: a longitudinal study of mediation processes in a representative sample of US adolescents. Psychol Addict Behav 2008; 22:269.

29. Weaver JB, Mays D, Weaver SS, Kannenberg W, Hopkins GL, Eroĝlu D, et al. Health-risk correlates of video-game playing among adults. Am J Prev Med 2009; 37:299-305.

30. Ballard M, Gray M, Reilly J, Noggle M. Correlates of video game screen time among males: body mass, physical activity, and other media use. Eat Behav 2009; 10:161-167.

31. Maddison R, Mhurchu CN, Jull A, Jiang Y, Prapavessis H, Rodgers A. Energy expended playing video console games: an opportunity to increase children's physical activity? Pediatr Exerc Sci 2007; 19:334.

32. Ferguson CJ. Blazing angels or resident evil? Can violent video games be a force for good? Rev Gen Psychol 2010; 14:68.

33. Gentile DA, Swing EL, Lim CG, Khoo A. Video game playing, attention problems, and impulsiveness: Evidence of bidirectional causality. Psychol Popul Media Cult 2012; 1:62.

34. Clark AC, Ernst JV. Gaming in technology education: the study of gaming can teach life skills for the twentyfirst century that employers want... these include 
analytical thinking, team building, multitasking, and problem solving under duress. Technol Teach 2009; 68:21-27.

35. Beullens K, Roe K, Van den Bulck J. Video games and adolescents' intentions to take risks in traffic. $\mathrm{J}$
Adolesc Health 2008; 43:87-90.

36. Polman H, De Castro BO, van Aken MA. Experimental study of the differential effects of playing versus watching violent video games on children's aggressive behavior. Aggress Behav 2008; 34:256-264. 